\title{
Hematological profile of anemic pregnant women attending antenatal hospital
}

\author{
Sharma P. ${ }^{1}$, Nagar R. ${ }^{2}$ \\ 1 Research Scholar, Department of Home Science, University of Rajasthan, Jaipur \\ 2 Professor, Department of Home Science, University of Rajasthan, Jaipur
}

\begin{abstract}
Objective : To study the hematological profile of anemic pregnant women who were attending antenatal hospital.

Material and Methods : Pregnant women who had hemoglobin value of $<11$ gm were selected. Total 66 anemic pregnant women were enrolled for the study.. Pretested questionnaire was used to collect general information. Blood samples were collected by qualified technician for hematological estimation.

Results : Out of total 66 anemic pregnant women who participated, 11 (16\%) belong to age group $<20,36$ (54\%) belong to 20-25 and 19 (30\%) were from > 25 years. Out of 66, 28 (42\%) belong to primi gravidae, 26 (39\%) multigravidae and 12 (19\%) belong to grand multi gravidae. Among 66 participants, $40.92 \%$ were mild anemic, $54.54 \%$ were moderate and $4.54 \%$ were severe anemic. Other hematological parameters like RBC, $M C V, H C T, M C H C, M C H$ were also below the normal range.

Conclusion: There is a need to monitor hematological parameters during pregnancy and thereby improve the outcome of pregnancy.
\end{abstract}

Key Words : Pregnancy, Hematological parameters, Anemia, gravidae.

\section{Introduction:}

Anemia is defined as the most common hematological disorder during pregnancy having decreased hemoglobin level or circulating red blood cells. Inadequate intake or absorption of iron in conjunction with blood loss during pregnancy may contribute to anemia ${ }^{1}$. Anemia is the most common nutritional deficiency disorder in the world. WHO has estimated that prevalence of anemia in pregnant women was found $14 \%$ in developed, $51 \%$ in developing countries and $65-75 \%$ in India. About one third of the global population (over 2 billion) is anemic. Prevalence of anemia in all the groups is higher in India as compared to other developing countries. $^{2}$

The World Health Organization (WHO) recommends that hemoglobin ideally should be maintained at or above $11.0 \mathrm{~g} / \mathrm{dl}$, and should not be allowed to fall below $10.5 \mathrm{~g} / \mathrm{dl}$ in the second trimester. ${ }^{3}$

Anemia contributes to low birth weight and miscarriages and it is also a primary cause of low immunity of both the mother and the child, which make them vulnerable to several insfections. ${ }^{4}$

Iron absorption during pregnancy is determined by the amount of iron in diet, its bioavailability (meal composition) and the changes in iron absorption that occurs during pregnancy. Iron requirements are greater in pregnancy than in non-pregnant stage. Although iron requirements are reduced in 1st trimester because of absence of menstruation these raised steadily thereafter as high as $\geq 10 \mathrm{mg} / \mathrm{day}^{5}$.

Pregnancy is one of the most and unique periods of women's life cycle. Though it is the most exciting period of expectations and fulfillments, but it is a condition of great stress because many anabolic activities takes place and foetal growth is accomplished extensive changes in maternal body composition and metabolism. Maternal nutrition is the most important determinant influence during the development of foetus. Poor nutritional status during pregnancy is associated with inadequate weight gain, anemia, retarded foetal growth low birth weight, still births, preterm delivery, intrauterine growth retardation, morbidity and mortality rates . ${ }^{6}$ The hematological status in pregnant women can be analyzed by collection of blood samples during each of three trimesters, measuring different variables such as Packed Cell volume (PCV), mean corpuscular hemoglobin $(\mathrm{MCH})$, mean corpuscular hemoglobin concentration $(\mathrm{MCHC})$, mean corpuscular volume (MCV), red blood cell (RBC) count, white blood cell (WBC) count, hemoglobin concentration. ${ }^{7}$

The study was aimed to determine the hematological profile of anemic pregnant women who were attending antenatal hospital.

\section{Materials and Methods:}

A total of 66 anemic pregnant women who were attending antenatal hospital, willing to participate were selected randomly for this study. Prior permission from ethical committee of the hospital was taken. Data was collected through standardized questionnaire. Standardized techniques were used for the biochemical estimations. Blood samples were collected by qualified technician. Venous blood samples were drawn from 
mothers for the assessment of hematological parameters. EDTA tubes were used for blood sample collection. RBC count, PCV, hemoglobin concentration and other parameters were assessed by automated counter. The reference values for pregnant women used in this study were hemoglobin: 11g/dl, HCT: $35-49 \%$, MCV: 8090\%fL, MCHC: 31-37\%, MCH: 25-35Pg and RBC: 4.0-5.2 million/cmm.

\section{Inclusion Criteria}

$>$ Pregnant women age group 18-35 yrs.

$>$ Both vegetarian and non-vegetarian

\section{Exclusion Criteria :}

$>$ Obesity

$>$ Diabetes

$>$ Any complication related to pregnancy.

\section{Materials :}

$>$ Pretested questionnaire for age, education, trimester, religion.

$>$ Hematological estimation done by autoanalyser.

Test
Hb (Hemoglobin)
$>\mathrm{MCV}$ (Mean corpuscular volume)
$>\mathrm{RBC}($ Red blood cell $)$
$>$ MCHC (Mean corpuscular hemoglobin concentration)
$>\mathrm{MCH}($ Mean corpuscular hemoglobin)
$>\mathrm{HCT}($ Hematocrit $)$

\section{Collection of sample:}

The written consent of pregnant women was obtained prior to collection of blood sample. First the general information was collected through questionnaire, then blood sample was collected through qualified technician. Analysis was done on the same day of blood collection.

\section{Observation and Results: \\ Table I:}

Hematological Profile according to age group

\begin{tabular}{|l|c|c|c|c|c|c|c|}
\hline Age group & Number & $\begin{array}{c}\text { Mean } \\
\mathrm{Hb} / \mathrm{g} / \mathrm{dl}\end{array}$ & $\begin{array}{c}\text { RBC } \\
\left(10^{6} / \mu \mathrm{l}\right)\end{array}$ & $\begin{array}{c}\text { HCT } \\
(\%)\end{array}$ & $\begin{array}{c}\text { MCV } \\
(\mathrm{fl})\end{array}$ & $\begin{array}{c}\text { MCH } \\
(\mathrm{pg})\end{array}$ & $\begin{array}{c}\text { MCHC } \\
(\mathrm{g} / \mathrm{dl})\end{array}$ \\
\hline$<20$ & 11 & 8.10 & 3.52 & 29.43 & 77.79 & 21.17 & 27.42 \\
& $(16 \%)$ & \pm 0.70 & \pm 0.33 & \pm 3.46 & \pm 2.67 & \pm 2.58 & \pm 3.37 \\
\hline $20-25$ & 36 & 9.56 & 3.78 & 31.24 & 79.49 & 24.47 & 27.67 \\
& $(54 \%)$ & \pm 1.12 & \pm 0.43 & \pm 3.60 & \pm 2.99 & \pm 2.86 & \pm 2.80 \\
\hline$>25$ & 19 & 7.74 & 3.56 & 32.20 & 76.23 & 23.03 & 28.04 \\
& $(30 \%)$ & \pm 0.52 & \pm 0.47 & \pm 3.01 & \pm 2.53 & \pm 2.96 & \pm 2.45 \\
\hline
\end{tabular}

Table 2:

Hematological Profile according to Trimester

\begin{tabular}{|l|c|c|c|c|c|c|c|}
\hline Trimester & Number & $\begin{array}{c}\text { Mean } \\
\mathrm{Hb} / \mathrm{g} / \mathrm{dl}\end{array}$ & $\begin{array}{c}\text { RBC } \\
\left(10^{6} / \mu \mathrm{l}\right)\end{array}$ & $\begin{array}{c}\text { HCT } \\
(\%)\end{array}$ & $\begin{array}{c}\text { MCV } \\
(\mathrm{fl})\end{array}$ & $\begin{array}{c}\text { MCH } \\
(\mathrm{pg})\end{array}$ & $\begin{array}{c}\text { MCHC } \\
(\mathrm{g} / \mathrm{dl})\end{array}$ \\
\hline 2nd & 49 & 7.78 & 3.56 & 28.38 & 77.52 & 21.32 & 26.32 \\
Trimester & $(74 \%)$ & \pm 0.39 & \pm 0.47 & \pm 2.43 & \pm 4.32 & \pm 2.50 & \pm 2.94 \\
\hline 3rd & 17 & 8.28 & 3.63 & 29.44 & 78.32 & 21.53 & 28.47 \\
Trimester & $(26 \%)$ & \pm 0.64 & \pm 0.38 & \pm 3.45 & \pm 4.50 & \pm 2.63 & \pm 3.50 \\
\hline
\end{tabular}


Table 3:

Hematological Profile according to Gravidae

\begin{tabular}{|l|c|c|c|c|c|c|c|}
\hline Gravidae & Number & $\begin{array}{c}\text { Mean } \\
\mathrm{Hb} / \mathrm{g} / \mathrm{dl}\end{array}$ & $\begin{array}{c}\text { RBC } \\
\left(10^{6} / \mu \mathrm{l}\right)\end{array}$ & $\begin{array}{c}\text { HCT } \\
(\%)\end{array}$ & $\begin{array}{c}\text { MCV } \\
(\mathrm{fl})\end{array}$ & $\begin{array}{c}\text { MCH } \\
(\mathrm{pg})\end{array}$ & $\begin{array}{c}\text { MCHC } \\
(\mathrm{g} / \mathrm{dl})\end{array}$ \\
\hline Primi & 28 & 8.26 & 3.75 & 29.43 & 77.62 & 21.57 & 28.48 \\
gravidae & $(42 \%)$ & \pm 0.72 & \pm 0.38 & \pm 3.46 & \pm 3.42 & \pm 2.76 & \pm 2.32 \\
\hline Multi & 26 & 8.15 & 3.63 & 28.39 & 78.59 & 21.15 & 27.62 \\
gravidae & $(39 \%)$ & \pm 0.62 & \pm 0.40 & \pm 3.42 & \pm 3.98 & \pm 2.56 & \pm 2.84 \\
\hline Grand multi & 12 & 7.88 & 3.54 & 28.32 & 75.43 & 21.00 & 26.13 \\
gravidae & $(19 \%)$ & \pm 0.49 & \pm 0.43 & \pm 2.42 & \pm 3.53 & \pm 2.46 & \pm 3.72 \\
\hline
\end{tabular}

Table 4 :

Hematological Profile according to Religion

\begin{tabular}{|l|c|c|c|c|c|c|c|}
\hline Religion & Number & $\begin{array}{c}\text { Mean } \\
\mathrm{Hb} / \mathrm{g} / \mathrm{dl}\end{array}$ & $\begin{array}{c}\text { RBC } \\
\left(10^{6} / \mu \mathrm{l}\right)\end{array}$ & $\begin{array}{c}\text { HCT } \\
(\%)\end{array}$ & $\begin{array}{c}\text { MCV } \\
(\mathrm{fl})\end{array}$ & $\begin{array}{c}\text { MCH } \\
(\mathrm{pg})\end{array}$ & $\begin{array}{c}\text { MCHC } \\
(\mathrm{g} / \mathrm{dl})\end{array}$ \\
\hline Hindu & $40(60 \%)$ & 7.62 & 3.52 & 28.37 & 76.72 & 21.23 & 27.67 \\
& & \pm 0.67 & \pm 0.33 & \pm 3.45 & \pm 3.73 & \pm 1.45 & \pm 2.32 \\
\hline Muslim & $26(40 \%)$ & 8.15 & 3.73 & 29.42 & 78.23 & 23.43 & 28.42 \\
& & \pm 0.72 & \pm 0.43 & \pm 2.54 & \pm 3.43 & \pm 2.33 & \pm 2.43 \\
\hline
\end{tabular}

Table 5 :

Hematological Profile according to Educational Level

\begin{tabular}{|l|c|c|c|c|c|c|c|}
\hline $\begin{array}{l}\text { Education } \\
\text { al Level }\end{array}$ & Number & $\begin{array}{c}\text { Mean } \\
\mathrm{Hb} / \mathrm{g} / \mathrm{dl}\end{array}$ & $\begin{array}{c}\text { RBC } \\
\left(10^{6} / \mu \mathrm{l}\right)\end{array}$ & $\begin{array}{c}\text { HCT } \\
(\%)\end{array}$ & $\begin{array}{c}\text { MCV } \\
(\mathrm{fl})\end{array}$ & $\begin{array}{c}\text { MCH } \\
(\mathrm{pg})\end{array}$ & $\begin{array}{c}\text { MCHC } \\
(\mathrm{g} / \mathrm{dl})\end{array}$ \\
\hline Illiterate & $14(21 \%)$ & 7.64 & 3.29 & 28.23 & 76.23 & 22.52 & 27.32 \\
& & \pm 0.73 & \pm 0.43 & \pm 2.47 & \pm 3.83 & \pm 2.12 & \pm 2.52 \\
\hline Literate & $9(13 \%)$ & 8.17 & 3.71 & 28.73 & 78.93 & 22.53 & 28.32 \\
& & \pm 0.74 & \pm 0.48 & \pm 2.45 & \pm 3.43 & \pm 2.42 & \pm 3.53 \\
\hline Primary & $26(39 \%)$ & 8.79 & 3.73 & 29.42 & 77.82 & 23.54 & 28.30 \\
& & \pm 0.82 & \pm 0.44 & \pm 3.43 & \pm 2.43 & \pm 3.42 & \pm 3.52 \\
\hline High & $10(15 \%)$ & 8.93 & 3.79 & 29.71 & 76.91 & 24.51 & 29.32 \\
School & & \pm 0.91 & \pm 0.33 & \pm 3.27 & \pm 2.52 & \pm 2.32 & \pm 2.53 \\
\hline Graduate & $7(12 \%)$ & 9.12 & 3.81 & 30.21 & 78.24 & 24.52 & 29.42 \\
& & \pm 0.94 & \pm 0.35 & \pm 4.23 & \pm 3.52 & \pm 2.32 & \pm 3.42 \\
\hline
\end{tabular}

The classification of anemia as per the degree of severity was found to be $40.92 \%$ as mild anemic, $54.54 \%$ as moderate anemic while $4.54 \%$ as severe anemic.

Figure 1. Distribution according to the degree of severity of anemia and the basis of $\mathrm{Hb}$ level.

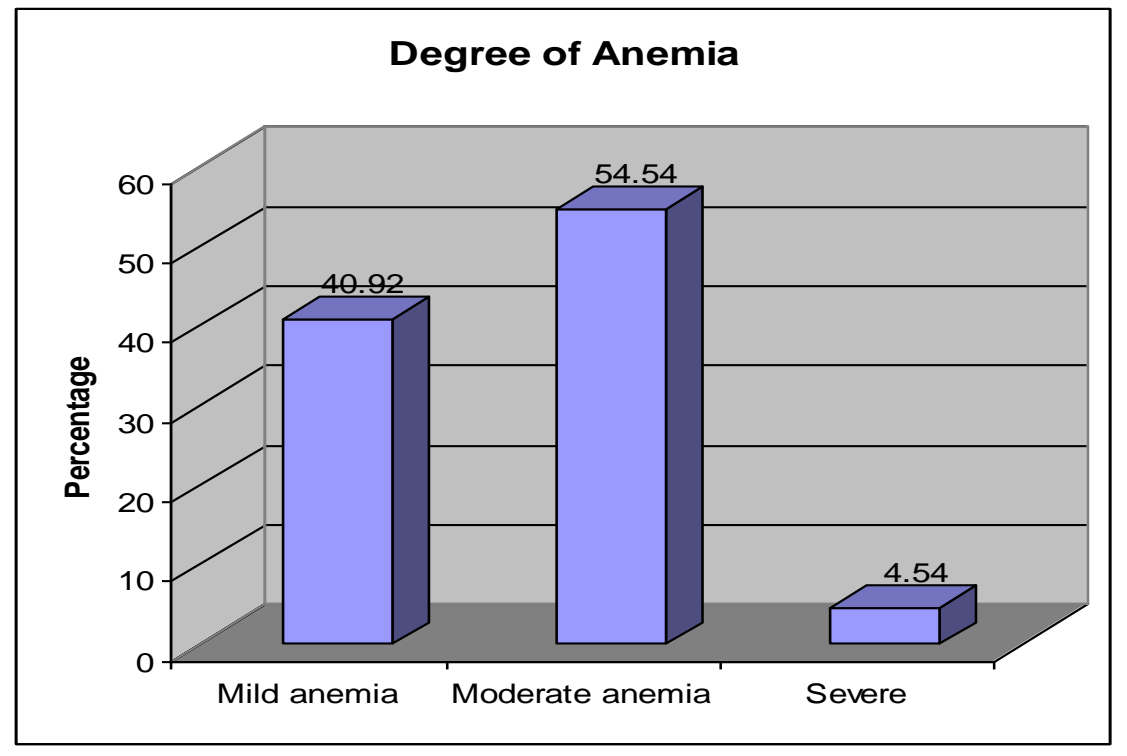


$>$ Table 1 represents the hematological profile of anemic pregnant women according to their age group. Results shows that hemoglobin and other parameters below the normal range in all age groups.

$>$ Table 2 represents the hematological profile of anemic pregnant women according to their trimester. It shows that in $3^{\text {rd }}$ trimester hemoglobin and other parameters were below normal range as compared to $2^{\text {nd }}$ trimester.

$>$ Table 3 represents the hematological profile of anemic pregnant women according to their gravidae. It shows that women who belong to grand multi gravidae reported hemoglobin and other values much lower as compared to women who belong to primi-gravidae.

$>$ Table 4 represents the hematological profile of anemic pregnant women according to their religion. Hindu pregnant women were more anemic as compared to muslim pregnant women.

$>$ Table 5 represents the hematological profile of anemic pregnant women according to their educational level. It shows that women who were illiterate reported hemoglobin and other hematological values below as compared to women who were educated.

> Fig:-1 represents the degree of anemia in pregnant women according to hemoglobin level. It shows that $40.92 \%$ women were mild anemic, $54.54 \%$ as moderate anemic while $4.54 \%$ as severe anemic .

\section{Disscussion :}

In this study out of 66 pregnant women $40.92 \%$ were mild anemic, $54.54 \%$ were moderate anemic while $4.54 \%$ were severe anemic. According to Shah. et al. $(2012)^{8}$ out of 51 pregnant anemic women $9(18 \%)$ were mildly anemic, $30(58 \%)$ were moderately anemic while $9(18 \%)$ were severely anemic and $3(6 \%)$ were very severe anemic.

In the present study mean $\mathrm{RBC}$ were $3.52,3.78,3.56$ in the age group $<20,20-25$ and $>25$ respectively. Mean MCV were 77.79, 79.49, 76.23.MCH were 21.17, 24.47, 23.03 and MCHC were 27.42, 27.67, and 28.04 in the above age group. Mean HCT were 29.43, 31.24 and 32.20 in the age group <20, 20-25 and $>25$ respectively. In another study done by Javed et al $2001^{9}$ overall mean RBC $\left(10^{6} / \mu \mathrm{l}\right)$, PCV $(\%), \mathrm{Hb}(\mathrm{g} / \mathrm{dl})$, $\mathrm{MCV}(\mathrm{fl}), \mathrm{MCH}(\mathrm{Pg})$ and $\mathrm{MCHC}(\mathrm{g} / \mathrm{dl})$ were $4.00,34.49,9.69,90.23,25.63$ and 28.80 observed in pregnant women age group of $<25,26-32$ and $>33$ years.

In the study done by P.U. Okeke (2011) ${ }^{10}$ who observed the prevalence of maternal anemia was $38.8 \%$. The mean of hemoglobin in the anemic population was $10.1 \mathrm{gm} / \mathrm{dL}$, HCT $35 \%$, MCV $87.5 \mathrm{fL}$ and RDW-CV 13.5\%. In another study by Sunitha et al (2010), RBC level in anemic pregnant women was observed as 3.70, 3.69 and 3.56 in the age group of 15-24, 25-34 and >35 respectively which was similar to the present study where RBC level were 3.52, 3.78 and 3.56 in the age group of $<20,20-25$ and $>25$. In the present study hemoglobin concentration was 8.10, 9.56 and 7.74 in above age group while in the study of Sunitha $e t$ al hemoglobin level of pregnant women were 8.27, 8.63 and 9.08 observed in second trimester. MCV level in their study were $80.76,80.35$ and 80.86 in the second trimester of pregnant women in these age groups comparable to present study that were $77.79,79.49$ and 76.23 . $\mathrm{MCH}$ level in their study were $22.56,23.60$ and 24.41 while in the present study it was $21.17,24.47$ and 23.03 respectively. In the present study level of MCHC were 27.42, 27.67 and 28.04 which was comparable with the study of Sunitha et al $(2010)^{11}$.

\section{Conclusion:}

There is a need to monitor these parameters during pregnancy.Anemia is a silent killer. The high prevalence of anemia,despite the availability and easy access to medical care,indicates the level of ignorance and indifference to health needs. There is an urgent need to educate pregnant women and their families about the importance of antenatal care.

\section{Acknowledgements :}

The authors are thankful to Dr Seema mehta and the antenatal hospital where the study was carried out.

\section{References:}

[1] CS. Gautam,L. Saha,K. Sekhri and Saha PK.. Iron deficiency in pregnancy and rationality of iron supplements prescribed during pregnancy. Medscape J. Med. 10 (12), 2008, 283.

[2] Dc Mayer EM, Tegman A. Prevalence of Anemia in the World. World Health Organ Qlty 1998; 38 : 302-316.

[3] World Health Organization. Prevention and management of severe anemia in pregnancy. Report of a Technical Working Group, Geneva, 20-22 May 1991. Maternal Health and Safe Motherhood Programme, Geneva : WHO; 1993.

[4] Imam TS, Yahaya A. Packed cell volume of pregnant women attending Dawakin Kudu General Hospital, Kano state, Nigeria. Int Jor P App Scs ; 2(2), 2008; 46-50.

[5] Hallberg L. Iron balance in pregnancy. In : Berger H. (Ed.) Vitamins and minerals in pregnancy and lactation. New York : Raven Press : 1988, 115-127.

[6] Kansal B, Guleria K, Agarwal N, Sethi K . Effect of maternal nutritional supplementation on foetal growth parameters and doppler flow velocity in growth restricted foetuses. Ind J Nutr Dietet,41:2004,198-204.

[7] James TR, Reid HL., Mullings MA. Are Published standards for haematological indices in pregnancy applicable across population. An evaluation in healthy pregnant Jamacian women. BMC Pregnancy Child Birth, 8, 2008, 8. 
[8] Amar R Shah, Neha D Patel, Menka H Shah. Hematological parameters in anemic pregnant women attending the antenatal clinic of rural teaching hospital, Innovative Journal of Medical and Health Science 2., 2012, 70-73.

[9] Muhammad T. Javed, Naheed Abbas, Riffat Hussain, Tahir Zahoor. A study on iron deficiency anemia and hematological differences around delivery in women of different socio-economic and age groups. Medical Journal of Islamic Academy of Sciences 14(4), 2001, 151-160.

[10] Okeke P.U. Anemia in pregnancy -is it a Persisting public health problem in Proto Novo-Cape Verde? Research Journal of Medical Sciences 5 (4), 2011, 193-199

[11] Sunitha P. Satyanarayana N., Shaik M.M., Mobina S., Lakshmi K.B., Kathi M.C., Pradeep B. Hematological responses to oral administration of iron polymoltose complex in anemic and normal pregnant women :A comparative study. Journal of College of Medical Sciences-Nepal, 6(3), 2010, 1-7. 